fundus which have never been described in association with tropical eosinophilia strengthened our suspicion and we decided to start treatment with steroids and antileukaemic drugs, e.g. 6-mercaptopurine and Myleran. Enlargement of lymph nodes, sternal tenderness and leukaemic retinitis have been descrited in association with eosinophilic leukaemia (Norlander, 1951).

Odeberg (1965) after a critical review of the literature was unable to find a single case of uncomplicated eosinophilic leukaemia and found evidence of multi-system involvement some time or other. According to him eosinophilic leukaemia and disseminated eosinophilic collagen disease (DECD) may be variants of the same condition. Pulmonary infiltration as revealed in the serial X-rays, enlargement of the lymph nodes, sternal tenderness, ocular changes and hepatosplenomegaly in our case undoubtedly point towards widespread involvement of various organs, consistent with the description of Engfeldt \& Zetterstroms (1965) who considered this as a separate entity. We feel that our case satisfies the criteria of both these groups of workers and provides additional evidence that eosinophilic leukaemia and disseminated eosinophilic collagen disease are but two stages or aspects of the same disease.

\section{Acknowledgments}

We are extremely grateful to Professor C. V. Harrison for the microscopic study of the lymph node and his generous help in getting the child admitted in the Royal Postgraduate Medical School. We are no less grateful to Professor J. V. Dacie and Dr Scopes who very kindly sent us the case note summary covering the period of their supervision. It would have been impossible to publish this without their help and co-operation.

\section{References}

Bentley, H.P. JR., ReARdon, A.E., KNoedler, J.P. \& Krivit, W. (1961) Eosinophilic leukemia. American Journal of Medicine, 30, 310.

Chen, H.P. \& Sмiтh, H.S. (1960) Eosinophilic leukemia. Annals of Internal Medicine, 52, 1343.

DAmeshek, W. \& Gunz, F. (1964) Leukaemia, 2nd edn, p. 226, Grune and Stratton, New York.

ENGFELDT, B. \& ZetTERSTROM, R. (1956) Disseminated eosinophilic collagen disease. Acta medica scandinavica 153, 337.

Islam, N. (1964) Tropical Eosinophilia, p. 62. Postgraduate Medicine, Dacca, Bangladesh.

Norlander, N.B. (1951) Eosinophilic leukemia infiltrating the Gasserian ganglion. Acta medica scandinavica, 177, 129.

Odeberg, B. (1965) Eosinophilic leukemia and disseminated eosinophilic collagen disease-a disease entity? Acta medica scandinavica, 177, 129.

Wintrobe, M.M. (1967) Clinical Haematology, 6th edn, p. 1022. Lea \& Febiger, Philadelphia.

\title{
Haemorrhage and fever in the Munchausen syndrome
}

\author{
J. C. ANDERSON \\ M.B., M.R.C.P.
}

\author{
P. W. EWAN \\ M.B., B.S.
}

\author{
N. D. COMPSTON \\ M.D., F.R.C.P.
}

\section{Royal Free Hospital, Lawn Road, London, N.W.3}

A CASE of the Munchausen syndrome (Asher, 1951) is described, the main features of which were recurrent gastro-intestinal haemorrhage and later, a pyrexia of unknown origin.

\section{Case report}

In 1961, at the age of 24 years, the patient, a staff nurse, began to complain of intermittent epigastric pain sometimes related to meals. Initial investigations, which included a barium meal, showed no abnormality.

The symptoms persisted, and 2 years later the pain was followed by haematemesis. For the next 4 years shehad intermittent haematemesis and melaena which often resulted in substantial blood loss, and required frequent transfusion.

During this time she was extensively and repeatedly investigated both in her own hospital and in a specialist unit. Repeated barium radiography, gastroscopy etc. were normal, and no bleeding diathesis was demonstrated. Two exploratory laparotomies revealed no abnormality after a thorough examination of the whole gastro-intestinal tract.

Two and a half years after the onset of symptoms an elective vagotomy and pyloroplasty was performed. A small, healing acute duodenal ulcer was 
found, but the symptoms remained unchanged. Five months later a gastroscopy was carried out immediately after a bleed, and a subtotal gastrectomy followed. Histology of the operation specimen showed no specific change. Recurrent haemorrhage persisted.

In 1967 she also developed quite frequent and profuse epistaxes, at first treated by nasal cautery. At this time she was referred to the Royal Free Hospital for a further opinion. At her first attendance as an out-patient a marked abnormality of her clotting mechanism was demonstrated and she was subsequently admitted. Repeat tests, however, failed to show any bleeding diatheses.

After admission to hospital the nature of her illness changed. While she still complained of indigestion there was little evidence of further gastro-intestinal bleeding. She now developed a low grade fever, at first associated with an abscess in one of her abdominal scars.

Over the next 2 years her fever persisted, following no definite pattern, but ranging between $99^{\circ} \mathrm{F}$ and $105^{\circ} \mathrm{F}$. She spent much of the first year in hsopital, and was again thoroughly investigated. Her haemaglobin now remained fairly constant at $12 \mathrm{~g}$, her ESR did not exceed $7 \mathrm{~mm} / \mathrm{hr}$, and she had a mild intermittent leucocytosis. No other investigation showed any abnormality, blood cultures being persistently negative. Recurrent abscesses in her abdominal scars were troublesome, and led to a further fruitless surgical exploration. Recurrent cellulitic lesions also appeared on her hands and feet, biopsy of which showed a chronic inflammatory reaction. Her fever was not significantly altered by intravenous penicillin in high dosage for 2 weeks, nor by a trial of corticosteroids.

Following a period of out-patient observation in 1968, she was re-admitted again in 1969 essentially unchanged. It was noted that the recurrent cellulitis usually occurred in accessible parts of her feet, legs, abdomen and left hand, but not in her right hand. Since she was right-handed the suspicion that these lesions were self-induced arose, bringing with it the whole possibility of factitious disease. Simple thermometer manipulation appeared unlikely, since oral and rectal temperatures had teen confirmed with constant rectal monitoring of temperature using a galvanometer.

However, it was noted that, on occasions, she did not show a tachycardia commensurate with her fever, neither did she seem always flushed and sweaty when febrile. These features were more in favour of factitious fever produced by thermometer manipulation. A thermometer was secretly marked and given to her, and she was found to return a different one. She was thus exposed, and there followed a full explanation of her previous disease.

\section{Confession}

For the 4 years between 1963 and 1967 she had simulated haematemesis and melaena by venesecting herself, usually using an Intracath taken from the ward on which she worked. She then ingested blood and later vomited it, often in the presence of witnesses. Melaena was repeatedly produced in the same way. On more than one occasion self-venesection had led to syncope.

Towards the end of this period, venesection became more difficult. She had then resorted to producing epistaxes by nasal trauma, and she made these more prolonged and severe by the self-administration of heparin, obtained from the ward supply beforehand. Indeed, when she first attended the Royal Free Hospital as an out-patient, she injected herself with heparin on the train to London, thus accounting for the abnormality found.

Persistent and recurrent wound infections were produced by the injection of milk into her scars, using disposable syringes again obtained from the ward. This frequently produced a mild fever, but she later found that the cause of her fever could be made more mysterious by injecting herself intravenously with a mixture of heparinized blood, taken from herself, and milk. Sometimes this 'cocktail' was kept in a syringe for some days prior to use, and occasion ally it was injected subcutaneously, thus producing an area of cellulitis.

Occasionally she spared herself this trouble and resorted to simple thermometer manipulation having a spare thermometer pre-set at a higher, reading, and returning this to the nurse instead of the original by a polished sleight of hand.

\section{Discussion}

This patient had been simulating illness for 6 years during which time she had been subjected repeatedly to expensive and unpleasant investigations, had been transfused with over 50 units of blood, had spent many unnecessary months in a hospital bed, and, not least, had undergone several major, dangerous and mutilating operations.

The risks she had taken had been considerable. She had bled herself to the point of syncope, her haemoglobin falling to as low as $4 \mathrm{~g} / 100 \mathrm{ml}$. She had injected herself intravenously with a substance which was potentially highly infected, producing fever as high as $106^{\circ} \mathrm{F}$. She had used anticoagulants irresponsibly.

In retrospect, it may seem surprising that she was not discovered earlier. This is partly due to her ingenuity, and to a versatility unusual in Asher's 'Munchausen' syndrome. Factitious anaemia produced by self-bloodletting has been described previously, in one case being treated by partial gastrectomy (Daily, Coles \& Creger, 1963; Steinbeck, 
1961). Factitious fever due to thermometer manipulation is also reported (Thompson et al., 1964) and in one series of fourteen cases of spurious fever (Petersdorf \& Bennett, 1957), twelve were women and five nurses.

As a nurse she had several advantages. She knew ward routine well, and was well prepared for thermometer rounds. She had easy access to syringes, needles, heparin, etc., and understood how to use and dispose of them. Her motive, however, as in many cases of this syndrome, is not readily apparent. It may be significant that she first bled herself when working on a busy ward with more responsibility at home, when she helped her mother cope with a dependent father and two younger brothers. Her illness spared her this burden.
She, herself, gave no good reason for her deceit, but admitted to considerable relief when discovered, there being no need to continue. She readily accepted the need for psychiatric help and rehabilitation, and is progressing satisfactorily.

\section{References}

Asher, R. (1951) Munchausen syndrome. Lancet, i, 339.

Daily, W.J.R., Coles, J.M. \& Creger, W.P. (1963) Factitious anaemia. Annals of Internal Medicine, 58, 533.

Petersdorf, R.G., \& Bennett, I.L. (1957) Factitious fever. Annals of Internal Medicine, 46, 1039.

SteinbeCK, A.W. (1961) Haemorrhagiae histrionica. Medical Journal of Australia, 48, 451.

Thompson, G.W., Shuster, J., Williams, R.L. \& Kaye, M. (1964) Munchausen syndrome, a cause of pyrexia of unknown origin. Canadian Medical Association Journal, 91, 1021. 